\title{
Back to the future: ketamine and nitrous oxide in major refractory depression
}

\begin{abstract}
Major depression is a serious health problem that affects children, adolescents, adults and the elderly, most often in females. Traditional antidepressants have a high rate of therapeutic failure, with suicide being frequent during the beginning of treatment. Ketamine administered by diverse routes in subanesthetic doses and the inhalation of nitrous oxide have shown a sharp reduction of the indicators of major depression. The molecular mechanisms of action of these general anesthetics have been very controversial and most of the studies involve the NMDA receptor, although there is new evidence pointing to non-NMDA receptors as an important part of the rapid antidepressant effects of ketamine. ketamine (intravenous, nasal, sublingual, oral, intramuscular, subcutaneous) results in a rapid and effective treatment for depression with few side effects. It is most frequently given as $0.5 \mathrm{mg} / \mathrm{kg}$ intravenous infusion, and the results are perceived few hours after its administration, lasting up to 2 weeks. Future knowledge of the underlying molecular mechanisms, the therapeutic results and the immediate and long-term side effects of ketamine and nitrous oxide guarantee the development of a novel generation of fast-acting antidepressant drugs.
\end{abstract}

Volume 9 Issue 3 - 2017

\author{
Victor MWhizar-Lugo MD,' Cesar Heredia- \\ Mota MD,' Alejandro Camacho MD² \\ 'Intensive Care Unit, Hospital General de Tijuana, ISESALUD, \\ México \\ ${ }^{2}$ School of Medicine Universidad Autónoma de Baja California, \\ Tijuana BC, México
}

Correspondence: Victor MWhizar-Lugo MD, Hospital General de Tijuana, ISESALUD, Av. Centenario I085I, Zona Rio, Tijuana B.C., México Zip Code 22,320, Tel +52-664-6848905, Fax +52-664-6848906, Email vwhizarl@gmail.com

Received: December 20, 2017 | Published: December 28, 2017

\section{Glutamate system}

\section{Introduction}

Major depression (MD) is a very common chronic mental illness that causes substantial disability in millions of adolescents and adults throughout the world. In the United States of North America there is an annual risk of depression of $6.6 \%$. Unfortunately, only $30-40 \%$ of patients will remit with the usual antidepressant drugs and there is a high risk of suicide attempts during the first month of treatment. Patients who do not respond to antidepressants have a poor quality of life with symptoms and risks as diverse as panic disorders, phobias, anxiety, anhedonia, impaired sexual satisfaction, unacceptable social behavior, low mood, attempts to suicide, just to name a few. There are several options to treat major depressive disorder, including psychotherapy, pharmacotherapy, electroconvulsive therapy, transcranial magnetic stimulation, as well as non-traditional approaches. ${ }^{1-4}$

Selective serotonin reuptake inhibitor antidepressants (SSRIs) are the first-line of treatment for major depressive disorder, although selective inhibitors of norepinephrine reuptake and other drugs with related mechanisms that act on specific neurotransmitters are also used. ${ }^{5}$. Unfortunately, most antidepressants require many weeks or months to achieve their therapeutic effects, and in more than $50 \%$ of patients the result is not adequate. This has led to the investigation of new targets with antidepressant effects such as neurokinins, cytokines, corticotropin, release factor, opioids, cannabinoid receptor, and others. ${ }^{6}$ The unapproved use (off label use) of drugs with approved indications for other pathologies is a notable option for patients who have diseases refractory to existing authorized treatment. Several drugs used in anesthesia have been studied off label use in several diseases or symptoms of systemic pathologies with fascinating results. The mechanisms of action of some these drugs are understood thanks to recent advances in the knowledge of membrane receptors, transmitters and their interactions. Ketamine and nitrous oxide are current examples off label use indications that have been the subject of various investigations in animals and humans. We review the most recent advances in the use of ketamine and nitrous oxide -antagonists of NMDA receptors- in the management of patients with refractory major depression to traditional antidepressants.
Considering the extensive evidence of the involvement of the glutamate system in the pathophysiology of depression, it is important to review this system briefly. Glutamate is the main excitatory neurotransmitter in the CNS of mammals, including the human brain and is known to play an important role in cell plasticity. There are two large groups of glutamate receptors; ion channels (ionotropic receptors) and G-protein coupled receptors (metabotropic receptors), which play an important role for excitatory synaptic transmission and neuronal plasticity. The ionotropic glutamate receptors are multimeric sets of four and are divided into three groups based on their structural and pharmacological similarities; NMDA (N-methyl-D-aspartate), AMPA ( $\alpha$-amino-3-hydroxyl-5-methyl-4-isoxazole-propionate), and kainite receptors (kainic acid) (Figure 1). All ionotropic glutamate receptors are non-selective cation channels, which allows the passage of $\mathrm{Na}^{+}$and $\mathrm{K}^{+}$, and in some instances small amounts of $\mathrm{Ca}^{2+}$. NMDA, AMPA and kainate are formed from the association of protein subunits that can be mixed in various ways to produce a large number of receptor isoforms. The NMDA glutamate receptor subfamily also forms multiple subunits, non-selective cation channels include the subunits NR1, NR2 (NR2A-NR2D). It is thought that the glutamate binding site is in the NR2 subunit, while the NR1 subunit contains the binding site for glycine. Within the ion channel of this receptor is the site $\mathrm{S}$ and the site phencyclidine, the latter is the place where ketamine acts. ${ }^{7-9}$ It has been shown that glutamate receptors mediate the excitatory responses in the CNS and their synaptic connections depend on the dynamic interaction of the NMDA, AMPA and kainate receptors.

\section{Ketamine}

Ketamine hydrochloride (CI-581) is non-competitive anesthetic, with high affinity and antagonist of NMDA glutamate receptors. It is a drug related to phencyclidine (PCP, angel dust) that was synthesized in 1962 by Calvin Stevens when he was looking for a new intravenous anesthetic. Ketamine was first patented in Belgium in 1963, and introduced by Domino et al in clinical anesthesia in 1966. ${ }^{10-12}$ It was 
approved for use in humans by the FDA in 1970. Since then, this compound has been used successfully in various anesthesia techniques, with patients of all ages, in a wide variety of clinical settings. In addition, several non-anesthetics uses of ketamine have been described as a bronchodilator, antidepressant, in chronic pain, as well as preemptive analgesic. Its main side effects are hallucinations, which can be reduced or avoided with benzodiazepines or butyrophenones such as droperidol. It is a racemic compound, where S-ketamine is 4 times more potent than the R-ketamine isomer (Figure 2). In hippocampal neurons, S-ketamine also inhibits NMDA receptors more potently than R-ketamine, reflecting relative stereoselectivity in vivo. ${ }^{7}$

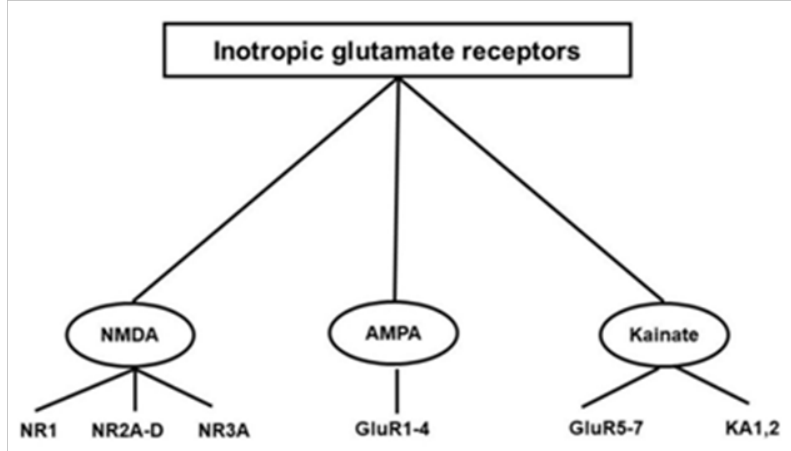

Figure I Classes of inotropic glutamate receptors.

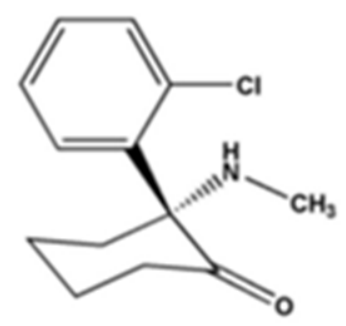

(\$)-Ketamine

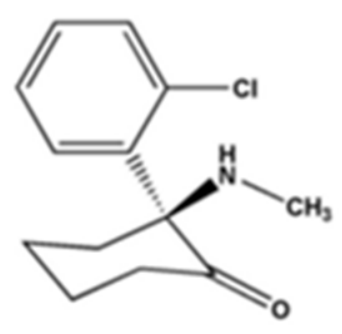

(R)-Ketamine
Figure 2 Ketamine $S$ and $R$ isomers.

The neuropharmacological properties of ketamine have prompted clinical research using it as a novel rapid and short-acting antidepressant. A single dose produces antidepressant effects within hours of administration, peak in less than a day, and last up to two weeks. ${ }^{13-15}$

Antidepressant mechanisms: The antidepressant mechanisms of ketamine are controversial and appear to be multiple; in part through the release of glutamate at NMDA receptors, the AMPA receptor contributes to the NMDA receptor and apparently to metabotropic receptors, which may represent a convergent mechanism for rapid antidepressant actions of ketamine. ${ }^{16-19}$ However, these effects were also found in the 5-HT and dopamine receptors of the mammalian rapamycin pathway (mTOR). ${ }^{17,20-22}$ Muthukumaraswamy et al. ${ }^{23}$ mention that this antidepressant effect of ketamine may depend on its ability to change the balance of frontoparietal connectivity patterns.

Recently, Zanos et al. ${ }^{24}$ proposed that $(2 \mathrm{~S}, 6 \mathrm{~S} ; 2 \mathrm{R}, 6 \mathrm{R})-$ hydroxynorketamine (HNK) - a metabolite of racemic ketamineproduces antidepressants effects in mice. These actions are independent of NMDAR inhibition but implicate early and sustained activation of $\alpha$-amino-3-hydroxy-5-methyl-4-isoxazole propionic acid receptors (non-NMDA receptors). This theory was also mentioned by Hashimoto. ${ }^{25}$ This enantiomer lacks ketamine related side effects. This novel hypothesis has motivated interesting comments ${ }^{26,27}$ and new therapeutic possibilities will surely be opened without the undesirable effects of ketamine, including the possibility of addiction when used chronically. On the other hand, Shirayama and Hashimoto ${ }^{28}$ found that the HNK (20 and $40 \mathrm{mg} / \mathrm{kg}$ ) does not have antidepressant effects in a rat model of depression.

Although there are currently many studies in animals and humans, the clinical data to treat patients with psychiatric disorders resistant to the usual treatment such as unipolar and bipolar depression, refractory obsessive disease, post-traumatic malaise, anxiety and suicide, exhibit controversial results since there are many questions without satisfactory answers.

In just two hours after the administration of ketamine, patients improve the symptoms of MD, which contrasts with the slow response to the traditional antidepressants. This rapid response has cataloged ketamine as a novel ultra-rapid onset antidepressant that begins to have an important place in therapeutic armamentarium for these patients.

The first double-blind study comparing intravenous ketamine 0.5 $\mathrm{mg} / \mathrm{kg}$ versus placebo $^{29}$ in patients with MD demonstrated significant improvement measured with the Hamilton scale in the patients treated with ketamine. Carrier and $\mathrm{Kabbak}^{30}$ found that female rats are more sensitive to the antidepressant effect of low doses of ketamine when compared to male rats and female ovariectomized rats where no antidepressant effect was found. These authors suggest an important hormonal role. This animal data is relevant since MD affects more women than men.

There is no consensus on the dose and ideal route for the administration of ketamine as an antidepressant in MD disorders. Most studies have used intravenous infusions with subanesthetic doses ranging from 0.25 to $0.5 \mathrm{mg} / \mathrm{kg}$ administered in 40 to 60 minutes in a variety of schemes: a weekly infusion for two weeks, 3 to 5 times a week for a week. ${ }^{16,31}$ Correll and Futter ${ }^{32}$ described two patients managed with very low doses $(0.1-0.2 \mathrm{mg} / \mathrm{kg} / \mathrm{h})$ and adjusted to 0.27 $\mathrm{mg} / \mathrm{kg} / \mathrm{h}$ with excellent results.

The antidepressant effect lasting up to two weeks after the infusion of ketamine $0.5 \mathrm{mg} / \mathrm{kg}$ has been related to the family history of alcoholism. ${ }^{33}$ Pennybaker et al. ${ }^{34}$ treated 93 patients with MDD or bipolar depression with a single infusion of ketamine $0.5 \mathrm{mg} / \mathrm{kg}$ that only $12.9 \%$ had response criteria two weeks later. These authors found that ketamine responder have a positive family history of alcoholism in a first-degree relative and greater dissociative effect during ketamine administration. They also mentioned that better measurements in sadness, failure to feel, and difficulty concentrating at day 1 after ketamine infusion correlated most powerfully with antidepressant effects at two weeks evaluation.

The antidepressant effect of ketamine occurs almost immediately after the intravenous administration is completed; the onset occurs within two hours post infusion and persists significantly for a week evaluated with the Hamilton scale. Like its use in anesthesiology, ketamine as antidepressant drug has been administered intravenous, oral, sublingual, subcutaneous, intramuscular and intranasal, with promising results..$^{35-37}$ In a randomized, double-blind, crossover study that included 20 patients with MD, Lapidus and his group ${ }^{38}$ found that $50 \mathrm{mg}$ of intranasal ketamine for two consecutive days had a rapid antidepressant effect with minimal side effects. Children aged 9-19 years suffering bipolar disorder (Fear of Harm (FOH) phenotype) were treated with intranasal ketamine producing marked improvement 
in all symptoms. ${ }^{39}$ The nasal route could be the ideal approach in the management of these patients since it is easily accessible compared with parenteral options. In elderly patients with resistant depression ketamine produced significative and sustained improvement of depressive symptoms. ${ }^{40}$

Suicidal thoughts and suicide are an important part of people affected by MD. The rapid effect of ketamine on MD decreases the frequency of suicidal ideation, and this is one of the greatest advantages of this novel treatment. ${ }^{41}$.Single ketamine intravenous infusion $0.5 \mathrm{mg} / \mathrm{kg}$ over 40 minutes administered in patients with MDD and bipolar depression could reduce suicidal ideas by reducing nocturnal wakefulness by an unknown mechanism. ${ }^{42}$ In a recent randomized clinical trial including 80 patients suffering MDD Grunebaum et al. ${ }^{43}$ compared $0.5 \mathrm{mg} / \mathrm{kg}$ i.v. ketamine versus $0.02 \mathrm{mg} /$ $\mathrm{kg}$ i.v. midazolam and measured SSI score 24 hours after, and found that ketamine demonstrated a larger and faster reduction in suicidal thoughts within 24 hours compared with midazolam. Ketamine side effects were brief, and clinical improvement lasted up to 6 weeks with additional optimized standard pharmacotherapy in an uncontrolled follow-up.

Fatigue is an accompanying symptom of depression that can be treated with ketamine. A recent study showed that $0.5 \mathrm{mg} / \mathrm{kg}$ of ketamine administered in 40 minutes significantly reduced for two weeks the fatigue scores in patients with bipolar disorders when compared to placebo in a double-blind crossover study. ${ }^{44}$ While there are abundant clinical and animal references, a recent review has called into question the antidepressant effects of ketamine and mentions the need for more research. ${ }^{45}$

As it has been reviewed, ketamine in low doses has a fast antidepressant effect in MD, in bipolar depression, and in depression with suicidal ideas. ${ }^{13,44,45}$ One limitation to this novel management is the relatively short time that ketamine has as an antidepressant and the addictive potential that patients could develop. ${ }^{46,47}$

\section{Nitrous oxide}

Named "dephlogisticated nitrous air" by its creator, nitrous oxide $\left(\mathrm{N}_{2} \mathrm{O}\right)$ was first prepared by Joseph Priestley in 1722. In 1800 Sir Humphry Davy mentioned the possibility of using it in surgery due to its analgesic properties. Since then, the gas of laughter has had a wellknown history with personalities such as William Parker, Gardner Q. Colton, Horacio Wells, William Morton, John Collins Warren. Curiously, it was Horacio Wells who introduced $\mathrm{N}_{2} \mathrm{O}$ as an anesthetic gas in his failed presentation at the Massachusetts General Hospital. Wells had data compatible with MD and seasonal affective disorder that recurred in the winter and resolved in the spring and is known to self-breathe $\mathrm{N}_{2} \mathrm{O},{ }^{48}$ which would make him the first patient to receive $\mathrm{N}_{2} \mathrm{O}$-pure serendipity- for MD.

Nagele and his group ${ }^{49}$ based their research on the fact that being $\mathrm{N}_{2} \mathrm{O}$ an NMDA receptor antagonist could have a therapeutic effect on resistant $\mathrm{MD}^{50}$ like that described with ketamine. They studied 20 patients with resistant $\mathrm{MD}$ comparing $50 \% \mathrm{~N}_{2} \mathrm{O}$ in oxygen versus a mixture of $50 \%$ nitrogen- $\mathrm{O}_{2}$ administered for 60 minutes. Symptoms of MD improved significantly at 2 and 24 hours compared with the placebo group. In three of 10 patients, $\mathrm{N}_{2} 0$ was discontinued, 4 had reduction $\geq 50 \%$ on the Hamilton scale, and 3 had complete remission. There were no severe side effects. Zarate and Machado-Viera ${ }^{51}$ commented on the results of Nagele and the possibilities of $\mathrm{N}_{2} \mathrm{O}$ in the management of resistant MD. Yang and Hashimoto ${ }^{52}$ also comment on the study of Nagele and his group adding comments on the effect of isofluorane and scopolamine on the NMDA receptor.

The toxicity of $\mathrm{N}_{2} \mathrm{O}$ could be a limiting factor to the chronic use in patients with resistant MD since it interacts with vitamin B12 inhibiting methionine synthetase, a key enzyme in the metabolism of methionine and folates. Although the classic exposure during anesthesia is not considered harmful, chronic exposure could cause megaloblastic depression in the bone marrow, neurological symptoms. A relationship between anesthesia with $\mathrm{N}_{2} \mathrm{O}$ and hyperhomocysteinemia has also been found, which is an independent risk factor for coronary heart disease. ${ }^{53,54}$

\section{Conclusion}

The modulating effect of general anesthetics on neuronal activity could exert long-term therapeutic results in certain psychiatric conditions such as MD disorders. ${ }^{52,55}$ The off-label use of drugs is accepted in medicine as long as it is based on studies in animals and humans that show encouraging results, with minimal or no side effects. This is the case of advances in the management of refractory MD and other psychiatric pathologies that have benefited from the antagonism of glutamate receptors by modifying human pathological behaviors by changing the chemical interactions of neurotransmitters/membrane receptors. ${ }^{56,57}$ Ketamine and $\mathrm{N} 2 \mathrm{O}$ are two general anesthetics from the past that have opened a range of future therapeutic possibilities in psychiatry by demonstrating promising results where traditional antidepressants have a high failure rate. As experts in the safe use of these two drugs, but unaware of psychiatric diseases, anesthesiologists can actively co-participate in this new modality of resistant MD management. In fact, most of the clinics that have opened in the United States of America are directed by anesthesiologists interested in this topic.

\section{Acknowledgments}

None.

\section{Conflicts of interest}

The authors declare no conflicts of interest.

\section{References}

1. Smith KM, Renshaw PF, Bilello J. The diagnosis of depression:current and emerging methods. Compr Psychiatry. 2013;54(1):1-6.

2. IsHak WW, Mirocha J, Christensen S, et al. Patient-reported outcomes of quality of life, functioning, and depressive symptom severity in major depressive disorder comorbid with panic disorder before and after SSRI treatment in the STAR*D trial. Depress Anxiety. 2014;31(8):707-716.

3. Riihimäki KA, Vuorilehto MS, Melartin TK, et al. Five-year outcome of major depressive disorder in primary health care. Psychol Med. 2014;44(7):1369-1379.

4. Riihimäki K, Vuorilehto M, Melartin T, et al. Incidence and predictors of suicide attempts among primary-care patients with depressive disorders:a 5-year prospective study. Psychol Med. 2014;4(2):291-302.

5. Amick HR, Gartlehner G, Gaynes BN, et al. Comparative benefits and harms of second generation antidepressants and cognitive behavioral therapies in initial treatment of major depressive disorder:systematic review and meta-analysis. BMJ. 2015;351:h6019.

6. Pacher P, Kecskemeti V. Trends in the development of new antidepressants. Is there a light at the end of the tunnel? Curr Med Chem. 2004;11(7):925-943. 
7. Purves D, Augustine GJ, Fitzpatrick D, et al. In Neuroscience. Chapter 7. Neurotransmitter receptors and their effects. Glutamate receptors. Sunderland MA. Sinauer Associates. 2001.

8. Forman SA, Chin VA. General anesthetics and molecular mechanisms of unconsciousness. Int Anesthesiol Clin. 2008;46(3):43-53.

9. http://www.bristol.ac.uk/synaptic/receptors/

10. Corssen G, Domino EF. Dissociative anesthesia:further pharmacologic studies and first clinical experience with the phencyclidine derivative CI-581. Anesth Analg. 1966;45(1):29-40.

11. Domino EF, Chodoff P, Corssen G. Pharmacologic effects of C1-581, a new dissociative anesthetic in man. Clin Pharmacol Ther. 1965;6:279291.

12. Corssen G, Miyasaka M, Domino EF. Changing concepts in pain control during surgery:dissociative anesthesia with CI-581. A progress report. Anesth Analg. 1968;47(6):746-759.

13. Abbasi J. Ketamine minus the trip:New hope for treatment-resistant depression. JAMA 2017;318(20):1964-1966.

14. Andrade C. Ketamine for depression, 1:Clinical summary of issues related to efficacy, adverse effects, and mechanism of action. $J$ Clin Psychiatry. 2017;78(4):e415-e419.

15. Lee EE, Della Selva MP, Liu A, et al. Ketamine as a novel treatment for major depressive disorder and bipolar depression:a systematic review and quantitative meta-analysis. Gen Hosp Psychiatry. 2015;37(2):178184.

16. Mathews DC, Zarate CA Jr . Current status of ketamine and related compounds for depression. J Clin Psychiatry. 2013;74(5):516-517.

17. Machado-Vieira R, Salvadore G, Diazgranados N, et al. Ketamine and the next generation of antidepressants with a rapid onset of action. Pharmacol Ther. 2009;123(2):143-150.

18. Hashimoto K. The role of glutamate on the action of antidepressants. Prog Neuropsychopharmacol Biol Psychiatry. 2011;35(7):1558-1568.

19. Murrough JW. Ketamine as a novel antidepressant:From synapse to behavior. Clin Pharmacol Ther. 2012;91(2):303-309.

20. Monteggia LM, Zarate C Jr. Antidepressant actions of ketamine:from molecular mechanisms to clinical practice. Curr Opin Neurobiol. 2015;30:139-143.

21. Krystal JH, Sanacora G, Duman RS. Rapid-acting glutamatergic antidepressants:the path to ketamine and beyond. Biol Psychiatry. 2013;73(12):1133-1141.

22. Dutta A, McKie S, Deakin JF. Ketamine and other potential glutamate antidepressants. Psychiatry Res. 2015;225(1-2):1-13.

23. Muthukumaraswamy SD, Shaw AD, Jackson LE, et al. Evidence that subanesthetic doses of ketamine cause sustained disruptions of NMDA and AMPA-mediated frontoparietal connectivity in humans. J Neurosci. 2015;35(33):11694-11706.

24. Zanos P, Moaddel R, Morris PJ, et al. NMDAR inhibitionindependent antidepressant actions of ketamine metabolites. Nature. 2016;533(7604):481-486.

25. Hashimoto K. Ketamine's antidepressant action:beyond NMDA receptor inhibition. Expert Opin Ther Targets. 2016;20(11):1389-1392.

26. Aleksandrova LR, Phillips AG, Wang YT. Antidepressant effects of ketamine and the roles of AMPA glutamate receptors and other mechanisms beyond NMDA receptor antagonism. J Psychiatry Neurosci. 2017;42(4):222-229.

27. Raffa RB, Pergolizzi JV Jr, Taylor R Jr. The rapid-onset antidepressant effect of ketamine:More surprises? J Clin Pharm Ther. 2017.
28. Shirayama Y, Hashimoto K. Lack of antidepressant effects of (2R,6R)hydroxynorketamine in a rat learned helplessness model:comparison with (R)-ketamine. Int J Neuropsychopharmacol. 2017;21(1):84-88.

29. Berman RM, Cappiello A, Anand A, et al. Antidepressant effects of ketamine in depressed patients. Biol Psychiatry. 2000;47(4):351-354.

30. Carrier N, Kabbaj M. Sex differences in the antidepressant-like effects of ketamine. Neuropharmacology. 2013;70:27-34.

31. Zarate CA Jr, Singh JB, Carlson PJ, et al. A randomized trial of an Nmethyl-D-aspartate antagonist in treatment-resistant major depression. Arch Gen Psychiatry. 2006;63(8):856-864.

32. Correll GE, Futter GE. Two case studies of patients with major depressive disorder given low-dose (subanesthetic) ketamine infusions. Pain Med. 2006;7(1):92-95.

33. Niciu MJ, Luckenbaugh DA, Ionescu DF, et al. Ketamine's antidepressant efficacy is extended for at least four weeks in subjects with a family history of an alcohol use disorder. Int $J$ Neuropsychopharmacol. 2014;18(1)pii:pyu039.

34. Pennybaker SJ, Niciu MJ, Luckenbaugh DA, et al. Symptomatology and predictors of antidepressant efficacy in extended responders to a single ketamine infusion. J Affect Disord. 2017;208:560-566.

35. Hartberg J, Garrett-Walcott S, De Gioannis A. Impact of oral ketamine augmentation on hospital admissions in treatment-resistant depression and PTSD:a retrospective study. Psychopharmacology (Berl). 2017.

36. Irwin SA, Iglewicz A, Nelesen RA, Lo JY, Carr CH, et al. (2013) Daily oral ketamine for the treatment of depression and anxiety in patients receiving hospice care:a 28-day open-label proof-of-concept trial. J Palliat Med 16(8):958-965.

37. Gálvez V, O’Keefe E, Cotiga L, Leyden J, Harper S, et al. (2014) Longlasting effects of a single subcutaneous dose of ketamine for treating melancholic depression:a case report. Biol Psychiatry 76(3):e1-2.

38. Lapidus KA, Levitch CF, Perez AM, et al. A randomized controlled trial of intranasal ketamine in major depressive disorder. Biol Psychiatry. 2014;76(12):970-976.

39. Papolos DF, Teicher MH, Faedda GL, et al. Clinical experience using intranasal ketamine in the treatment of pediatric bipolar disorder/fear of harm phenotype. J Affect Disord. 2013;147(1-3):431-436.

40. Medeiros da Frota Ribeiro C, Riva-Posse P. Use of ketamine in elderly patients with treatment-resistant depression. Curr Psychiatry Rep. 2017;19(12):107.

41. Sampath H, Sharma I, Dutta S. Treatment of suicidal depression with ketamine in rapid cycling bipolar disorder. Asia Pac Psychiatry. 2016;8(1):98-101.

42. Vande Voort JL, Ballard ED, Luckenbaugh DA, et al. Antisuicidal response following ketamine infusion is associated with decreased nighttime wakefulness in major depressive disorder and bipolar disorder. J Clin Psychiatry. 2017;78(8):1068-1074.

43. Grunebaum MF, Galfalvy HC, Choo TH, et al. Ketamine for rapid reduction of suicidal thoughts in major depression:A midazolamcontrolled randomized clinical trial. Am J Psychiatry. 2017.

44. Saligan LN, Luckenbaugh DA, Slonena EE, et al. An assessment of the anti-fatigue effects of ketamine from a double-blind, placebocontrolled, crossover study in bipolar disorder. J Affect Disord. 2016;194:115-119.

45. McCloud TL, Caddy C, Jochim J, et al. Ketamine and other glutamate receptor modulators for depression in bipolar disorder in adults. Cochrane Database Syst Rev. 2015;(9):CD011611.

46. Taiminen T. Ketamine as treatment for depression. Duodecim. 2017;133(1):52-60. 
47. Naughton M, Clarke G, O'Leary OF, et al. A review of ketamine in affective disorders:current evidence of clinical efficacy, limitations of use and pre-clinical evidence on proposed mechanisms of action. $J$ Affect Disord. 2014;156:24-35.

48. Martin RF, Desai SP. An examination of Horace Wells' life as a manifestation of major depressive and seasonal affective disorders. $J$ Anesth Hist. 2016;2(1):22-27.

49. Nagele P, Duma A, Kopec M, et al. Nitrous oxide for treatmentresistant major depression:A proof-of-concept trial. Biol Psychiatry. 2015;78(1):10-18.

50. Zorumski CF, Nagele P, Mennerick S, et al. Treatment-resistant major depression:Rationale for NMDA receptors as targets and nitrous oxide as therapy. Front Psychiatry. 2015;6:172.

51. Zarate CA Jr, Machado-Vieira R. Potential pathways involved in the rapid antidepressant effects of nitrous oxide. Biol Psychiatry. 2015;78(1):2-4.
52. Yang C, Hashimoto K. Combination of nitrous oxide with isoflurane or scopolamine for treatment-resistant major depression. Clin Psychopharmacol Neurosci. 2015;13(1):118-120.

53. Weimann J. Toxicity of nitrous oxide. Best Pract Res Clin Anaesthesiol. $2003 ; 17(1): 47-61$

54. El Otmani H, El Moutawakil B, Moutaouakil F, et al. Postoperative dementia: toxicity of nitrous oxide. Encephale. 2007;33(1):95-97.

55. Vutskits L. General anesthetics to treat major depressive disorder:Clinical relevance and underlying mechanisms. Anesth Analg. 2018;2018(126):208-216.

56. Gota V, Divatia JV. Off-label use of drugs:An evil or a necessity? Indian J Anaesth. 2015;59(12):767-768.

57. Schatzberg AF. A word to the wise about ketamine. Am J Psychiatry. 2014;171(3):262-264. 